\title{
СИСТЕМА ИСТОЧНИКОВ АДМИНИСТРАТИВНО-ПРАВОВОГО РЕГУЛИРОВАНИЯ КУЛЬТУРЫ
}

\begin{abstract}
Аннотация. В представленной статье автор рассматривает основополагающие источники административно-правового регулирования культуры, которые регулируют отношения в сфере сохранения и развития культуры в Российской Федерации, устанавливают правовые, организационные, экономические и социальные основы деятельности в данной сфере. Административно-правовое регулирование отношений в срере культуры и искусства основывается на положениях Конституции Российской Федерации и осуществляется национальным законодательством, включающим: Федеральные законы, иные нормативные правовые акты Российской Федерации. Автор в данной работе старается охватить весь спектр источников административно-правового регулирования культуры. Основным методом, применяемым в данной статье, является метод анализа основополагающих источников административно-правового регулирования культуры, которые регулируют отношения в сфере сохранения и развития культуры в Российской Федерации, устанавливают правовые, организационные, экономические и социальные основы деятельности в данной сфере. В своем исследовании автор затронул все самые последние изменения и дополнения в законодательстве касательно рассматриваемой сферы общественной жизни - культуры. В статье рассмотрены и деятельность Министерства культуры РФ, и задачи на 2015 год. Таким образом, автор выявляет существующие проблемы данной сферы и приходит к выводу о том, насколько выполнены эти задачи, как совершенствуется нормативнозаконодательная база сферы культуры и каково её дальнейшее развитие.
\end{abstract}

Ключевые слова: культура, культурная политика, административно-правовое регулирование, отношения сферы культуры, законодательство Российской Федерации, Источники административно-правового регулирования, нормативные правовые акты, Министерство культуры РФ, правовые основы, госприоритеты в туризме Abstract. The author considers the fundamental sources of public-legal regulation of the cultural sphere, which regulate the relations in the sphere of preservation and development of culture in the Russian Federation, establish legal, organizational, economic, and social grounds of activities in this sphere. Administrative-legal regulation of relations in the sphere of culture and art is based on the provisions of the Constitution of the Russian Federation and is realized by the national legislation including federal laws and other statutory instruments of the Russian Federation. The author attempts at covering all the range of sources of administrative-legal regulation of culture. The main research method is the method of analysis of the fundamental sources of administrative-legal regulation of culture which regulate the relations in the sphere of culture in the Russian Federation and establish the legal, organizational, economic and social grounds of activity in this sphere. The author touches upon all the recent changes of and amendments to the legislation related to the cultural sphere. The author analyzes the work of the Ministry of Culture and its tasks for 2015. The author detects the existing problems of this sphere and comes to the conclusion about the degree of implementation of these tasks, the ways of the normative-legal base improvement in the sphere of culture, and the prospects of its further development.

Key words: culture, cultural policy, administrative-legal regulation, relations in the cultural sphere, legislation of the Russian Federation, sources of administrative-legal regulation, statutory instruments, Ministry of Culture of the Russian Federation, legal grounds, national priorities in tourism.

фера культуры и искусства - одна из самых сложных для правового регулирования. Там,

где закон неизбежно сопрягается с миром нравственных ценностей и творческой воли, возникают коллизии, которые трудно, а порой, и не- возможно уложить в прокрустово ложе юридических норм.

В условиях формирования в Российской Федерации демократического правового государства все более значимыми становятся проблемы 


\section{Административное и муниципальное право 4 (100) 2016}

обеспечения прав и свобод человека, в том числе и в сфере культуры. Права человека выступают ценностным социально-правовым ориентиром функционирования всего государственного механизма. Реализация в полном объеме гарантированного Конституцией РФ широкого круга прав и свобод человека и гражданина - одна из приоритетных задач государственного и общественного развития России.

Признание культуры в качестве системообразующей ценности российского общества, вектора, задающего ориентир развития культурного потенциала российской нации, определяет необходимость совершенствования правового регулирования отношений в сфере культуры и пролонгирования государственных программ в данной сфере. Завершившийся 2014 г. согласно Указу Президента РФ был объявлен Годом культуры в России[15]. Соответственно, усилия органов государственной власти были направлены в том числе на совершенствование отечественного законодательства, регламентирующего отношения в сфере гарантирования, обеспечения и защиты культурных конституционных прав и свобод.

Как известно, основным нормативным правовым актом, до настоящего времени регламентирующим отношения в сфере реализации культурных прав и свобод, являются Основы законодательства РФ о культуре от 9 октября 1992 г.[23], которые принимались в рамках культурного и правового поля, существенно отличающегося от современных реалий. В связи с тем, что Основы законодательства РФ о культуре принимались более 22 лет назад, еще до принятия Конституции РФ 1993 г., представляет определенный научный интерес динамика развития этого нормативного правового акта.

\section{Административно-правовое регулирова-} ние культуры определяется:

- такими подзаконными нормативно-правовыми актами, как: Указ Президента РФ от 27.08.2007 N 1111 «0 Дне работника культуры»; Указ Президента РФ от 30.11.1992 г. N 1487 (ред. от 17.05.2007 г.) «Об особо ценных объектах культурного наследия народов Российской Федерации»; Распоряжение Правительства РФ от 10.06.2011 г. N 1019-р «0 Концепции развития театрального дела в Российской Федерации на период до 2020 года»; Постановление Правительства РФ от 15.04.2014 N 317 «0б утверждении государственной программы Российской Федерации «Развитие культуры и туризма» на 2013 - 2020 годы»; Постановление Правительства РФ от 3 марта 2012 г. N186 «0 федеральной целевой программе «Культура России (2012-2018 годы)» (в ред. от 10.09.2014 г.); Постановление
Правительства РФ от 20.07.2011 N 590 (ред. от 23.09.2014) «0 Министерстве культуры Российской Федерации» (вместе с «Положением о Министерстве культуры Российской Федерации»); Письмо Минкультуры РФ от 27.03.1998 г. N 01-73/16-30 «0 предоставлении информации о культурных ценностях в случае хищения из музеев и библиотек» и многие другие.

- Принимаемые в соответствии Конституцией, законами и иными нормативными правовыми актами, акты субъектов Российской Федерации, например: Закон Краснодарского края от 3 ноября 2000 г. № 325-К3 «О культуре» (в ред. 23.05.2014 г.); Закон Краснодарского края от 23 апреля 1996 г. № 28-К3 «О библиотечном деле в Краснодарском крае» (в ред. 14.09.2012 г.); Закон Краснодарского края от 6 февраля 2003 г. № 558-К3 «Об объектах культурного наследия (памятниках истории и культуры) народов Российской Федерации, расположенных на территории Краснодарского края» (в ред. 25.04.2014 г.) и ряд других.

- Общепризнанные принципы и нормы международного права и международные договоры Российской Федерации являются составной частью ее правовой системы. И здесь, особое внимание уделяется нормам содержащимся, в: Всеобщей декларации прав человека $\mathrm{OOH}$, 10.12.1948 г.), Международном пакте об экономических, социальных и культурных правах (OOH, 16.12.1966 г.), Декларации принципов международного культурного сотрудничества (ООН, 04.11.1966г.), Рекомендации об участии и вкладе народных масс в культурную жизнь $(\mathrm{OOH}, 26.11 .1976$ г.) Всеобщей декларации ЮНЕСКО о культурном разнообразии (ЮНЕСКО, 02.11.2001 г), Конвенции об охране и поощрении разнообразия форм культурного самовыражения (ЮНЕСКО, 20 октября 2005 г.), Конвенции о мерах, направленных на запрещение и предупреждение незаконного ввоза, вывоза и передачи права собственности на культурные ценности (ЮНЕСКО, 14.11.1970 г.), Европейской конвенции о защите прав человека и основных свобод (СЕ, 04.11.1950 г.), Европейской культурной конвенции (СЕ, 19.12.1954 г), Европейской социальной хартии (CE, 03.05.1996 г.), и многих других нормативно-правовых актах.

За период своего действия данный документ был полностью переработан и принят в новой редакции шесть раз. В настоящее время Комитетом Государственной Думы РФ по культуре, Министерством культуры РФ подготовлены и вынесены на публичное обсуждение проекты федеральных законов о культуре. 
Законотворчество продолжает оставаться одной из важнейших функций Минкультуры России. Министерство в своей законопроектной деятельности перешло к системному совершенствованию законодательного регулирования отдельных отраслей культуры и сферы культуры в целом.

В 2014 году Минкультуры самостоятельно и совместно с Государственной Думой разработан 21 законопроект, из которых принято 6 законов:

1) Федеральный закон от 22.10.2014 №315-Ф3 «0 внесении изменений в Федеральный закон «Об объектах культурного наследия (памятниках истории и культуры) народов Российской Федерации» и отдельные законодательные акты Российской Федерации», разработанный при активном участии Минкультуры, включил в себя 4 законопроекта Минкультуры:

- о включении в государственный кадастр недвижимости сведений о границах территорий объектов культурного наследия;

- об условиях льготной аренды объектов культурного наследия, находящихся в неудовлетворительном или аварийном состоянии;

- о приватизации объектов культурного наследия, находящихся в неудовлетворительном или аварийном состоянии;

- о совершенствовании системы учёта объектов культурного наследия в Едином реестре ОКН.

2) Федеральный закон от 04.10.2014 № 289-Ф3 «0 внесении изменений в Федеральный закон «0 банках и банковской деятельности», Федеральный закон «0 несостоятельности (банкротстве) кредитных организаций», Федеральный закон «Об архивном деле в Российской Федерации» (в части совершенствования требований к архивному хранению документов кредитными организациями).

3) Федеральный закон от 05.05.2014 № 102-Ф3 «0 внесении изменений в статью 12 Закона Российской Федерации «Основы законодательства Российской Федерации о культуре» (в части установлении права студентов на бесплатное посещение государственных и муниципальных музеев) внесен депутатами Государственной Думы при непосредственном участии Минкультуры России.

4) Федеральный закон от 05.05.2014 № 101-Ф3 «0 внесении изменений в Федеральный закон «0 государственном языке Российской Федерации» и отдельные законодательные акты Российской Федерации в связи с совершенствованием правового регулирования в сфере использования русского языка» включил в себя поправки Минкультуры о введении обязанности проката и показа фильма только при наличии прокатного удостоверения и установ- лении ответственности за несоблюдение данного условия.

5) Федеральный закон от 24.11.2014 № 364-Ф3 «0 внесении изменений в Федеральный закон «Об информации, информационных технологиях и о защите информации» и Гражданский процессуальный кодекс Российской Федерации включил в себя законопроект Минкультуры России в части внесудебного порядка прекращения нарушения авторских и смежных прав в сети Интернет.

6) Федеральный закон от 09.02.2015 №9-Ф3 «Об особенностях правового регулирования отношений в области культуры и туризма в связи с принятием в Российскую Федерацию Республики Крым и образованием в составе Российской Федерации новых субъектов - Республики Крым и города федерального значения Севастополя» принят Государственной Думой и одобрен Советом Федерации.

В области сохранения и популяризации культурного наследия в 2014 году были разработаны:

- проект федерального закона «0 внесении изменений в Федеральный закон «0 Музейном фонде Российской Федерации и музеях в Российской Федерации» (прошел рассмотрение в Правительстве Российской Федерации, 31.12.14 г. внесен в Государственную Думу Российской Федерации);

- проект федерального закона «0 коллекционировании и частных коллекциях в Российской Федерации» (рассматривается рабочей группой Государственной Думой Российской Федерации);

- проект федерального закона «О внесении изменений в Закон Российской Федерации «0 вывозе и ввозе культурных ценностей» (внесение законопроекта проходит в форме поправок в связи с принятием в первом чтении проекта аналогичного законопроекта № 549487-6 «0 ввозе культурных ценностей в Российскую Федерацию и вывозе культурных ценностей из Российской Федерации», внесенного депутатами Государственной Думы Российской Федерации);

- Правила выдачи, приостановления и прекращения действия разрешений (открытых листов) на проведение работ по выявлению и изучению объектов археологического наследия (утверждены постановлением Правительства Российской Федерации от 20.02.2014 № 127);

- внесены изменения в Положение о Министерстве культуры Российской Федерации (принято постановление Правительства Российской Федерации от 20.02.2014 № 126); 


\section{Административное и муниципальное право 4 (100) • 2016}

- разработан приказ Минкультуры России «0 порядке передачи государству археологических предметов, обнаруженных физическими и (или) юридическими лицами в результате проведения изыскательских, проектных, земляных, строительных, мелиоративных, хозяйственных или иных работ» (в соответствии с постановлением Правительства Российской Федерации от 25.08.2012 № 851 «0 порядке раскрытия федеральными органами 28 исполнительной власти информации о подготовке проектов нормативных правовых актов и их общественного обсуждения»).

В соответствии со ст.3 Закона №73-ФЗ «Об объектах культурного наследия»[11] памятники истории и культуры представляют собой объекты недвижимого имущества вместе с принадлежащими им произведениями живописи, декоративно-прикладного искусства, скульптурами. Такие памятники возникли в результате тех или иных исторических событий, и являются свидетельством различных цивилизаций, а также настоящими источниками знаний о развитии и зарождении культуры

При рассмотрении юридических норм, регламентирующих оборот культурного наследия в России, следует начать с федеральных стандартов оценки, утвержденных приказами Минэкономразвития России. Они определяют общие понятия и подходы к оценке, требования к ее проведению, цели процесса оценки и виды стоимости, а также требования к отчету об оценке и к его экспертизе. Однако, в настоящее время, единого стандарта, который бы отвечал за оценку памятников архитектуры, в российской практике нет. В связи с этим, Правительством Российской Федерации приняты некоторые программные документы, например, план мероприятий (так называемая, «дорожная карта») «Совершенствование оценочной деятельности», который был утвержден распоряжением Правительства Российской Федерации от 26 сентября 2013 г. N 1744-р (далее - дорожная карта), где основной упор делается на интеграцию Международных стандартов оценки (далее - MCO) в российскую практику оценки.

Подробнее этот процесс изложен в концепции формирования системы стандартов в сфере оценочной деятельности, принятой распоряжением Минэкономразвития России от 16.07.2014 года за №132Р-УА (далее - концепция). Положения данной концепции гласят о том, что в ближайшей перспективе необходимо обеспечить интеграцию положений международных стандартов оценки, разработанных Международным советом по стандартам оценки (далее - международные стандарты оценки), с отечественными стандартами, а впоследствии рассмотреть их непосредственное применение в российской практике. Данный процесс позволит обеспечить равенство национальной оценочной практики с общепризнанной в мире практикой. Кроме того, будет обеспечено большее доверие к деятельности оценщиков, а отчеты об оценке, выполненные российскими оценщиками, добьются международного признания.

Однако, определить ценность недвижимого объекта культурного наследия в денежном выражении весьма затруднительно, поскольку каждый памятник истории и архитектуры уникален. Действующее законодательство не содержит необходимой методики оценки недвижимых объектов культурного наследия, содержащей, помимо прочего, критерии оценки ценности таких объектов.

Для решения проблемы оценки зданий памятников был разработан проект Федерального закона «0 внесении изменений в Федеральный закон «Об оценочной деятельности в Российской Федерации»»[17], предусматривавший подготовку обязательного для применения Стандарта оценки памятников архитектуры. Предлагалось, что Стандарт должен содержать как учет преимуществ, обусловленных наличием исторической, архитектурной, мемориальной градостроительной или другой культурной значимости, так и установленные законодательством обременения прав пользования, владения и распоряжения. При этом согласно проекту Закона указанный Стандарт подлежал утверждению Правительством Российской Федерации. Однако, в дальнейшем этот законопроект был снят с рассмотрения. В пояснительной записке к названному проекту закона значилось, что «Европейские стандарты оценки исторической собственности не применимы для оценки отечественных объектов культурного наследия». Необходимо отметить, что объекты культурного наследия являются специфическими объектами правового регулирования. Следовательно, до принятия решений об их экономическом обороте все же надлежит разработать соответствующие нормативные акты по определению стоимости обозначенных объектов. При этом такие нормативные акты должны быть разработаны на федеральном уровне с привлечением специалистов в области экономики, искусствоведения, реставрации, то есть необходим комплексный подход для решения отмеченной проблемы. В противном случае памятники истории и архитектуры будут продаваться по остаточной стоимости без учета их исторической, научной, духовной ценности. Кроме того, существует проблема в отсутствии правил о необходимости подготовки уполномоченным органом заключений по отчетам оценщиков.

В 2014 году разработаны и утверждены нормативные правовые акты для реализации положе- 
ний Федерального закона «Об объектах культурного наследия (памятниках истории и культуры) народов Российской Федерации», направленные на регулирование порядка приемки работ по сохранению объекта культурного наследия, а также направленные на регулирование градостроительной деятельности в исторических поселениях в целях сохранения исторической застройки:

- приказ Минкультуры России от 13.02. 2014 № 237 «0б утверждении Порядка приемки работ по сохранению объекта культурного наследия»;

- приказ Минкультуры России от 27.03.2014 № 534 «Об утверждении Порядка включения населенного пункта в перечень исторических поселений федерального значения».

С целью нормативного правового регулирования осуществления полномочий по государственной охране объектов культурного наследия и для реализации новых положений Федерального закона от 22.10.2014 № 315-Ф3 «0 внесении изменений в Федеральный закон «Об объектах культурного наследия (памятниках истории и культуры) народов Российской Федерации» и отдельные законодательные акты Российской Федерации» подготовлены и проходят процедуру согласования со всеми заинтересованными сторонами следующие нормативные правовые акты:

- проект приказа Минкультуры России «Об утверждении Порядка выдачи задания на проведение работ по сохранению объекта культурного наследия, включенного в единый государственный реестр объектов культурного наследия (памятников истории и культуры) народов Российской Федерации, или выявленного объекта культурного наследия»,

- проект приказа Минкультуры России «Об утверждении Порядка выдачи разрешения на проведение работ по сохранению объекта культурного наследия, включенного в единый государственный реестр объектов культурного наследия (памятников истории и культуры) народов Российской Федерации, или выявленного объекта культурного наследия»,

- проект приказа Минкультуры России «Об утверждении Порядка согласования проектной документации на проведение работ по сохранению объекта культурного наследия, включенного в единый государственный реестр объектов культурного наследия (памятников истории и культуры) народов Российской Федерации, или выявленного объекта культурного наследия»,

- проект приказа Минкультуры России «0 внесении изменений в приказ Минкультуры России от 13.02.2014 № 237 «Об утверждении По- рядка приемки работ по сохранению объекта культурного наследия»,

- проект постановления Правительства Российской Федерации «0 внесении изменений в Положение о государственной историко-культурной экспертизе», утвержденное постановлением Правительства Российской Федерации от 15 июля 2009 г. № 569.

В рамках реализации положений Федерального закон от 01.12.2014 № 419- Ф3 «0 внесении изменений в отдельные законодательные акты Российской Федерации по вопросам социальной защиты инвалидов в связи с ратификацией Конвенции о правах инвалидов» подготовлен Проект приказа Минкультуры России «Об установлении порядка обеспечения условий доступности для инвалидов объектов культурного наследия».

В 2014 году Минкультуры России был подготовлен законопроект «0 внесении изменений в Федеральный закон «Об объектах культурного наследия (памятниках истории и культуры) народов Российской Федерации» (в части установления порядка выполнения международных обязательств, вытекающих из Конвенции об охране всемирного культурного и природного наследия 1972 года)», который призван упорядочить работу по следующим основным направлениям:

- формирование перечня объектов культурного наследия, рекомендуемых Российской Федерацией для включения в Список всемирного наследия;

- подготовка планов управления для объектов всемирного культурного наследия;

- необходимые условия при проектировании в целях проведения землеустроительных, строительных, мелиоративных и других работ на территории объекта всемирного наследия и его буферной зоны;

- обеспечение выполнения требований Конвенции в части подготовки периодического отчета государства о ее выполнении и проведения мониторинга состояния объекта всемирного наследия. Законопроект прошел в 2014 году необходимые межведомственные согласования и был направлен на заключение в Минюст России.

Федеральным законом от 22 октября 2014 года №315-Ф3 внесены изменения в Федеральный закон «Об объектах культурного наследия (памятниках истории и культуры) народов Российской Федерации» (далее - Федеральный закон), в соответствии с которыми порядок разработки проекта зон охраны объекта культурного наследия, проекта объединённой зоны охраны объектов культурного наследия, требования к режимам использования земель и градостроительным регламентам в 


\section{Административное и муниципальное право 4 (100) 2016}

границах территорий таких зон устанавливаются Правительством России.

Подписанным постановлением утверждено положение о зонах охраны объектов культурного наследия (памятников истории и культуры) народов России (далее - Положение).

Положением определены обязанности органов исполнительной власти субъектов Федерации, уполномоченных в области охраны объектов культурного наследия, по подготовке и согласованию разработанных проектов зон охраны объектов культурного наследия с Минкультуры России.

Кроме того, Положением определено, что в случае распространения на одну и ту же территорию в границах зоны охраны объекта культурного наследия разных режимов использования земель и градостроительных регламентов, на этой территории действуют более строгие режимы использования земель и градостроительные регламенты вне зависимости от уровня и даты принятия акта органа государственной власти, утвердившего такие режимы использования земель и градостроительные регламенты, а также категории историко-культурного значения объекта культурного наследия.

В статье 34 Федерального закона введено новое понятие «объединённая зона охраны объектов культурного наследия», которая устанавливается в целях одновременного обеспечения сохранности в исторической среде нескольких объектов культурного наследия. В связи с этим в Положении установлены основания разработки проекта объединённой зоны охраны и определён порядок принятия решения о разработке такого проекта. Принятые решения позволят усовершенствовать правовое регулирование в сфере охраны объектов культурного наследия.

За первую половину 2015 года приняты следующие законы:

1. Федеральный закон от 12.02.2015 №9-Ф3 «Об особенностях правового регулирования отношений в области культуры и туризма в связи с принятием в Российскую Федерацию Республики Крым и образованием в составе Российской Федерации новых субъектов - Республики Крым и города федерального значения Севастополя», разработанный Нормативно-правовым департаментом Минкультуры России и внесённый в Государственную Думу депутатами.

Целью закона является создание правовых условий для обеспечения сохранности объектов культурного наследия и культурных ценностей, находящихся в Республике Крым и городе федерального значения Севастополе.

Для достижения указанных целей закона предлагаются меры, которые позволят оперативно распространить правоотношения, действующие в сфере сохранения культурного наследия народов Российской Федерации, на объекты культурного наследия и культурные ценности Республики Крым и города федерального значения Севастополя. Кроме того, законом регулируются вопросы работы туроператоров, осуществляющих свою деятельность в Республике Крым и городе Севастополе. Предусмотренные законом решения позволят избежать дорогостоящих, трудозатратных и продолжительных по времени процедур, установленных законодательством Российской Федерации.

В отношении музейных предметов и музейных коллекций, уникальных и редких архивных документов, а также обязательного экземпляра документов, ценных, редких документов и коллекций библиотечного фонда Республики Крым и города Севастополя законопроектом предлагается одномоментно ввести их в нормативное пространство сферы сохранения культурных ценностей Музейного, Архивного, национального библиотечного и национального библиотечно-информационного фондов Российской Федерации путем признания их составной частью этих фондов. Эти меры позволят избежать утрат уникальных памятников истории и культуры Республики Крым и города Севастополя.

Также закон позволит применить имеющиеся правовые условия работы туроператоров, установленные Федеральным законом «Об основах туристской деятельности в Российской Федерации», к туроператорам, осуществляющим свою деятельность в Крыму.

2. Федеральный закон от 08.03.2015 №50-Ф3 «0 внесении изменений в статью 19 Федерального закона «О рекламе» и Федеральный закон «Об объектах культурного наследия (памятниках истории и культуры) народов Российской Федерации» (в части ограничения распространения наружной рекламы на объектах культурного наследия), разработанный Нормативно-правовым департаментом Минкультуры России.

Данный Закон устанавливает прямой запрет на распространение наружной рекламы на памятниках, ансамблях и их территориях. Объекты культурного наследия прежде всего являются свидетельством эпох, цивилизаций, и размещение на них наружной рекламы приводит не только к изменению их облика, но и нарушает целостность исторического и архитектурного замысла, у человека формируется искаженное художественное восприятие исторических ценностей, не говоря уже о том, что тяжеловесные рекламные конструкции влияют на устойчивость и сохранность памятников.

Реализация закона позволит сохранить исторический облик зданий и сооружений, отнесенных 
к памятникам истории и культуры, вместе с тем каких-либо излишних ограничений для предпринимателей он не вводит.

Помимо запрета на распространение наружной рекламы на памятниках, законопроект затрагивает и достопримечательные места. Здесь распространение наружной рекламы может быть ограничено федеральным или региональным органом охраны, а требования по ее ограничению вносятся в правила землепользования и застройки.

В то же время допускается распространение наружной рекламы, содержащей информацию о проводимых на территории памятника театрально-зрелищных, культурно-просветительных и зрелищно-развлекательных мероприятиях и информации о спонсорах, например, на афишах. Эти требования будут включаться в охранное обязательство собственника или законного владельца объекта культурного наследия.

3. Федеральный закон от 23.05.2015 №132-Ф3 «0 регулировании отдельных вопросов, связанных с проведением в Российской Федерации XV Международного конкурса имени П.И.Чайковского в 2015 году и внесении изменений в отдельные законодательные акты Российской Федерации», разработанный при участии Нормативно-правового департамента Минкультуры России и внесённый в Государственную Думу депутатами.

Закон устанавливает безвизовый въезд в Российскую Федерацию иностранных граждан, являющихся участниками и членами жюри конкурса, освобождает дирекцию конкурса от необходимости получения разрешения на привлечение и использование иностранных работников в качестве членов жюри конкурса, а члены жюри конкурса имеют право осуществлять трудовую деятельности на территории Российской Федерации без получения разрешения на работу или патента. Кроме того, выплаты и иные вознаграждения, производимые в пользу иностранных граждан, являющихся участниками и членами жюри конкурса, не облагаются страховыми взносами.

Оказание поддержки распространителям печатной продукции и расширение книжного пространства:

10 июня 2015 г. депутатами Государственной Думы внесён проект федерального закона «0 внесении изменения в статью 17.1 Федерального закона «0 защите конкуренции» (в части размещения книжных магазинов в государственных и муниципальных организациях культуры на льготных условиях), разработанный Нормативно-правовым департаментом Минкультуры России.

Законопроект предусматривает возможность заключения договоров аренды в отношении госу- дарственного и муниципального имущества организаций культуры, закрепленного за ними на праве оперативного управления, без проведения конкурсов или аукционов в порядке и на условиях, определяемых Правительством Российской Федерации.

Законопроект носит социально-экономический характер. Во-первых, позволит развиваться малому и среднему бизнесу в книжной сфере. Вовторых, доступность книг, которая последует с развитием книжной отрасли, увеличит образованность населения нашей страны и повысит культурный уровень граждан.

Принятие указанного законопроекта создаст определенный симбиоз между организациями культуры и книжными магазинами, повысит привлекательность предоставляемых культурных благ как одними, так и другими.

Во исполнение поручения Президента Российской Федерации от 30.07.2013 № Пр-1814 разработана и утверждена Стратегия развития туризма в Российской Федерации на период до 2020 года (распоряжение Правительства Российской Федерации от 31 мая 2014 г. № 941-p).

Стратегией определены основные государственные приоритеты в сфере туризма: совершенствование нормативно-правового регулирования, развитие доступной и комфортной туристской среды, создание единой системы продвижения туристских продуктов на внутреннем и международных туристских рынках. Разработан и утвержден План мероприятий по реализации Стратегии развития туризма в Российской Федерации на период до 2020 года (распоряжение Правительства Российской Федерации от 11.11.2014 № 2246-p). Планом предусмотрены меры по повышению качества и конкурентоспособности туристских продуктов, развитию туриндустрии, системы статистического учета, подготовке кадров.

В рамках совершенствования законодательства в сфере туризма, в 2014 году разработаны 7 проектов федеральных законов:

- 0 внесении изменений в отдельные законодательные акты Российской Федерации в целях усиления ответственности участников туристского рынка и повышения уровня правовой защиты туристов, выезжающих за пределы территории Российской Федерации (готовится к рассмотрению в первом чтении в Государственной Думе Федерального Собрания Российской Федерации);

- 0 внесении изменений в Федеральный закон «Об общих принципах организации местного самоуправления в Российской Федерации», в части чтения полномочия по созданию условий для развития туризма в вопросах органов местного само- 


\section{Административное и муниципальное право 4 (100) 2016}

управления (рассмотрен на расширенном заседании Экспертного совета Комитетом по социальной политики Совета Федерации Федерального Собрания Российской Федерации 16.12.2014);

- 0 внесении изменений в статью 219 части второй Налогового кодекса Российской Федерации, предусматривающий введение налоговых льгот для граждан Российской Федерации приобретающих путевки для совершения туризма и проведении отдыха на территории Российской Федерации;

- 0 внесении изменений в Налоговый кодекс Российской Федерации, предусматривающих предоставление налоговых льгот для работодателей при предоставлении работникам путевок для организации отдыха внутри страны; - 0 внесении изменений в Налоговый кодекс Российской Федерации, предусматривающих предоставление налоговых льгот для работодателей при предоставлении работникам туров для организации отдыха внутри страны, а также введение благоприятных налоговых условий в области туристско-рекреационной деятельности на территориях Дальневосточного федерального округа;

- 0 внесении изменения в статью 217 части второй Налогового кодекса Российской Федерации, которым предлагается отнести выплату премии Правительства Российской Федерации в области туризма к доходам физических лиц, которые не подлежат налогообложению (внесён в Правительство Российской Федерации);

- 0 внесении изменений в Федеральный закон «Об основах туристской деятельности в Российской Федерации», о поэтапном введении обязательной классификации гостиниц и иных средств размещения на территории Российской Федерации с 2018 года.

Во исполнение поручений Президента Российской Федерации, Правительства Российской Федерации, а также в целях реализации законодательства и осуществления полномочий по развитию сферы туризма в 2014 году разработано 16 нормативных правовых актов Правительства Российской Федерации и Минкультуры России, из них 11 принято, 5 - находятся на согласовании[19].

Нормативно-правовым департаментом продолжается работа над текстом проекта федерального закона «0 внесении изменений в отдельные законодательные акты Российской Федерации в целях усиления ответственности участников туристского рынка и повышения уровня правовой защиты туристов, выезжающих за пределы территории Российской Федерации» ко второму чтению.

Нормативно-правовым департаментом разработан проект федерального закона «0 внесении изменений в статьи 251 и 270 части второй Налогового кодекса Российской Федерации» (в части приведения в соответствие с положениями вышеуказанного законопроекта подпункта 18 пункта 2 статьи 251 и пункта 48.15 статьи 270 Налогового кодекса Российской Федерации).

Законопроектом предусматривается, что взносы членов объединения туроператоров в сфере выездного туризма в резервный фонд объединения туроператоров и фонды персональной ответственности туроператоров в сфере выездного туризма не будут учитываться в доходах такого объединения. Кроме того, произведенные за счет средств резервного фонда объединения туроператоров в сфере выездного туризма и фондов персональной ответственности туроператоров в сфере выездного туризма расходы не будут включаться в облагаемую прибыль объединения туроператоров в сфере выездного туризма.

Ведется создание условий для более активного привлечения иностранных специалистов к творческой деятельности на территории Российской Федерации. Нормативно-правовой департамент участвует в разработке проекта федерального закона «0 внесении изменений в Федеральный закон «0 правовом положении иностранных граждан в Российской Федерации» (в части отнесения иностранных специалистов, занимающихся творческой деятельностью, к высококвалифицированным специалистам).

Нормативно-правовым департаментом подготовлены поправки к проекту федерального закона «0 внесении изменений в отдельные законодательные акты Российской Федерации в части упрощения порядка получения деловой визы для некоторых категорий иностранных граждан», внесённому Законодательным Собранием СанктПетербурга и принятому в первом чтении (в части оформления визы в случаях прибытия иностранных артистов на непродолжительный срок с целью осуществления ими гастрольной деятельности).

Действующая Федеральная целевая программа «Культура России на 2012-2018 годы» дополняет правовое понимание культуры новыми элементами в содержании.

В ходе разработки указанной программы обсуждались два основных варианта комплекса мер, направленных на решение стоящих перед сферой культуры проблем. Первый комплекс мер (реалистичный) опирался на подходы, сформулированные в предыдущей одноименной федеральной целевой программе, и являлся ее логическим продолжением. Второй комплекс мер (оптимистичный) ориентировался на объективную потребность достижения стратегических целей и 
решения задач культурного развития страны, для чего выделяются приоритетные направления развития современного искусства, художественного образования, информатизации отрасли. Проведенный анализ действующей государственной программы свидетельствует, что выбран второй вариант выстраивания отношений в области культуры. Заслуживает внимания другая государственная программа в области культуры - «Развитие культуры и туризма на 2013-2020 годы», утвержденная Постановлением Правительства РФ от 15 апреля 2014 г. № 3172. Анализ основных целей данной программы говорит о понимании и декларировании единства, взаимообусловленности развития культуры и российской государственности. Например, в качестве целей реализации указанной государственной программы среди прочих заявлены: укрепление единого культурного пространства России как исторического государства - цивилизации, а также духовного единства многонационального народа Российской Федерации.

29 мая 2015 г. Правительством Российской Федерации внесён в Государственную Думу подготовленный Нормативно-правовым департаментом Минкультуры России отзыв Правительства Российской Федерации на проект федерального закона «О культуре в Российской Федерации», внесённый депутатами Государственной Думы. Ранее Минкультуры России разработало самостоятельный законопроект «О культуре в Российской Федерации». Было проведено его широкое общественное обсуждение на различных площадках, так как закон является базовым для сферы культуры и носит системообразующий характер.

В настоящее время Минкультуры России, депутатами Государственной Думы и членами Совета Федерации выработан единый подход к концепции правового регулирования сферы культуры. Все положения «министерского» законопроекта, которые прошли общественное обсуждение и получили поддержку со стороны творческих союзов, научного сообщества и деятелей культуры будут включены в окончательную редакцию законопроекта.

Проект федерального закона «0 культуре в Российской Федерации» возглавит группу отраслевых правовых актов Российской Федерации в области культуры; Проект федерального закона «О внесении изменений в отдельные законодательные акты в связи с принятием Федерального закона «0 культуре в Российской Федерации» (финансово-экономический блок).

Таким образом, нормативно-законодательная база сферы культуры постоянно совершенствуется, обеспечивая учет интересов всех заинтересованных сторон. Одной из задач современной России является обеспечение на всей ее территории единого культурного пространства, что включает в себя законодательные, институциональные и организационные гарантии устойчивого развития культурной среды. Актуальной проблемой современного российского законодательства является всестороннее исследование культуры и культурной политики, как на международном, так и государственном уровне.

Наряду с разработкой новых законодательных актов необходимо радикальное обновление ряда действующих федеральных законодательных актов. Для этого, к концу 2015 года предполагается активизировать подготовку проекта нового федерального закона о культуре в качестве базового акта, а также обновление законодательства регулирующего отношения в различных подотраслях культурной деятельности.

\section{Библиография:}

1. Конституция Российской Федерации (принята всенародным голосованием 12.12.1993 г.) (с учетом поправок, внесенных Законами РФ о поправках к Конституции РФ от 30.12.2008 г. N 6-ФКЗ, от 30.12.2008 г. N 7-ФКЗ, от 05.02.2014г. N 2-ФКЗ, от 21.07.2014г. N 11-ФКЗ) // Консультант Плюс.-Режим доступа URL: http://base.consultant. $\mathrm{ru} /$ cons/cgi/online.cgi?req=doc;base=LAW;n=2875 (дата обращения 12.10.2015 г.)

2. Федеральный закон от 29.12.1994 г. N 78-ФЗ «0 библиотечном деле» // «Российская газета» (Федеральный выпуск), № $4928,10.06 .010$. в ред. от 02.07.2013 г.

3. Закон РФ от 15.04.1993 г. N 4804-1 «0 вывозе и ввозе культурных ценностей» // "Российская газета", 15.05 .1993 г. N 92. в ред. от 23.07.2013 г.

4. Федеральный закон от 22.08.1996 г. N 126-Ф3 «О государственной поддержке кинематографии Российской Федерации» // "Собрание законодательства РФ", 26.08.1996, N 35, ст. 4136. в ред. от 05.05.2014 г.

5. Федеральный закон от 26.03.1998 г. N 41-Ф3 «0 драгоценных металлах и драгоценных камнях» // "Собрание законодательства РФ", 30.03.1998, N 13, ст. 1463. в ред. от 21.11.2011 г.

6. Федеральный закон от 15.04.1998 г. N 64-Ф3 «0 культурных ценностях, перемещенных в Союз ССР в результате Второй мировой войны и находящихся на территории Российской Федерации» // «Собрание законодательства Российской Федерации», 20.04.1998 г., N 16, ст. 1799. в ред. от 23.06.2008 г.

7. Федеральный закон от 26.05.1996 г. N 54-Ф3 «0 Музейном фонде Российской Федерации и музеях в Российской Федерации» // «Собрание законодательства Российской Федерации», 27.05.1996 г. N 22, ст. 2591. в ред. от 23.02.2011г. 


\section{Административное и муниципальное право 4 (100) • 2016}

8. Федеральный закон от 06.01.1999 г. N 7-Ф3 «0 народных художественных промыслах» // «Собрание законодательства Российской Федерации», 11.01.1999 г., N 2, ст. 234. в ред. от 25.12.2012 г.

9. Федеральный закон от 17.06.1996 г. N 74-Ф3 «0 национально-культурной автономии» // «Собрание законодательства Российской Федерации», 17.06.1996 г., N 25, ст. 2965. в ред. от 04.11.2014 г.

10. Федеральный закон от 22.10.2004 г. N 125-Ф3 «Об архивном деле в Российской Федерации» // «Собрание законодательства Российской Федерации», 25.10.2004 г. N 43 ст. 4169. в ред. от 04.10.2014 г.

11. Федеральный закон от 25.06.2002 г. N 73-Ф3 «Об объектах культурного наследия (памятниках истории и культуры) народов Российской Федерации» // "Российская газета", 29.06.2002 г. N 116-117. в ред. от 23.07.2013 г.

12. Федеральный закон от 13.12.1996 г. N 150-Ф3 «Об оружии» // "Собрание законодательства РФ", 16.12.1996, N 51, ст. 5681. в ред. от 21.07.2014 г.

13. Федеральный закон от 24.11.1996 г. N 132-Ф3 «Об основах туристской деятельности в Российской Федерации» // "Собрание законодательства РФ", 02.12.1996, N 49, ст. 5491. в ред. от 03.05.2012 г.

14. Закон РФ от 9.10.1992 г. N 3612-І «Основы законодательства Российской Федерации о культуре» // "Российская газета", 17.11.1992 г. N 248. в ред. от 21.07.2014 г.

15. Указ Президента РФ от 22.04.2013 г. № 375 «0 проведении в Российской Федерации Года культуры» // Собр. законодательства Рос. Федерации. 2013. № 17, ст. 2112.

16. Проект Федерального закона "О культуре в Российской Федерации" // Интернет-портал "Российской Газеты".-2011.-26 октября.-Режим доступа URL: http://www.rg.ru/2011/10/26/kultura-site-dok.html (дата обращения 12.10.2015 г.).

17. Проект Федерального закона «О внесении изменений в Федеральный закон "Об оценочной деятельности в Российской Федерации"» № 215711-4.

18. Доклад о результатах и основных направлениях деятельности Министерства культуры Российской Федерации за 2014 год и задачах на 2015 год. [Электронный ресурс]// Режим доступа: http://www.donland.ru/ Default. aspx?pageid=78774 (дата обращения 12.10.2015).

19. Государственный доклад о состоянии культуры в Российской Федерации в 2013 году [Электронный ресурс]// Режим доступа: http://mkrf.ru/upload/mkrf/mkdocs2014/doklad_block.pdf Дата обращения 12.10.2015.

20. Рекомендация ЮНЕСКО «Об участии и вкладе народных масс в культурную жизнь» (Найроби, 26 ноября 1976 г.) // Международные нормативные акты ЮНЕСКО.-М.: Логос, 1993. С. 340 - 352.

21. Калинин В.В. Культура в системе развития современного российского общества / В.В.Калинин // Культура: управление, экономика, право.-2007.-N 4.-C.15.

22. Подболотов П.А. Университет культуры и искусств как модель культурного пространства России / П.А. Подболотов // Культура: управление, экономика, право.-2009.-N 2.-С.33.

23. Хайруллин, Р. А. Основы государственной культурной политики [Текст] : реализация в сфере национально-культурных отношений / Р. А. Хайруллин.//Пробелы в российском законодательстве.-2015.-№ 1.-С. 30 - 32.

24. Ведомости СНД РФ и ВС РФ. 1992. № 46, ст. 2615; 2009. № 52, ч. 1, ст. 6411.

25. Берг Л.Н. Основные этапы российской правовой политики в сфере научной деятельности // Политика и Общество. - 2014. - 10. - C. 1155 - 1160. DOI: 10.7256/1812-8696.2014.10.11441.

26. Манзарханова Л.В. Междисциплинарный подход в исследовании традиционной культуры // Философия и культура. - 2014. - 2. - С. 190 - 194. DOI: 10.7256/1999-2793.2014.2.10766.

\section{References (transliterated):}

1. Konstitutsiya Rossiiskoi Federatsii (prinyata vsenarodnym golosovaniem 12.12.1993 g.) (s uchetom popravok, vnesennykh Zakonami RF o popravkakh k Konstitutsii RF ot 30.12.2008 g. N 6-FKZ, ot 30.12.2008 g. N 7-FKZ, ot 05.02.2014g. N 2-FKZ, ot 21.07.2014g. N 11-FKZ) // Konsul'tant Plyus.-Rezhim dostupa URL: http://base.consultant.ru/cons/cgi/online. cgi?req=doc;base=LAW;n=2875 (data obrashcheniya 12.10.2015 g.)

2. Federal'nyi zakon ot 29.12.1994 g. N 78-FZ «O bibliotechnom dele» // «Rossiiskaya gazeta» (Federal'nyi vypusk), № 4928 , 10.06.010. v red. ot 02.07.2013 g.

3. Zakon RF ot 15.04.1993 g. N 4804-1 «0 vyvoze i vvoze kul'turnykh tsennostei» // "Rossiiskaya gazeta", 15.05 .1993 g. $\mathrm{N}$ 92. v red. ot 23.07.2013 g.

4. Federal'nyi zakon ot 22.08.1996 g. N 126-FZ «0 gosudarstvennoi podderzhke kinematografii Rossiiskoi Federatsii» // "Sobranie zakonodatel'stva RF", 26.08.1996, N 35, st. 4136. v red. ot 05.05.2014 g.

5. Federal'nyi zakon ot 26.03.1998 g. N 41-FZ «0 dragotsennykh metallakh i dragotsennykh kamnyakh»// "Sobranie zakonodatel'stva RF", 30.03.1998, N 13, st. 1463. v red. ot 21.11.2011 g.

6. Federal'nyi zakon ot $15.04 .1998 \mathrm{~g}$. N 64-FZ «O kul'turnykh tsennostyakh, peremeshchennykh v Soyuz SSR v rezul'tate Vtoroi mirovoi voiny i nakhodyashchikhsya na territorii Rossiiskoi Federatsii» // «Sobranie zakonodatel'stva Rossiiskoi Federatsii», 20.04.1998 g., N 16, st. 1799. v red. ot 23.06.2008 g.

7. Federal'nyi zakon ot 26.05.1996 g. N 54-FZ «O Muzeinom fonde Rossiiskoi Federatsii i muzeyakh v Rossiiskoi Federatsii» // «Sobranie zakonodatel'stva Rossiiskoi Federatsii», 27.05.1996 g. N 22, st. 2591. v red. ot 23.02.2011 g.

8. Federal'nyi zakon ot 06.01.1999 g. N 7-FZ «0 narodnykh khudozhestvennykh promyslakh» // «Sobranie zakonodatel'stva Rossiiskoi Federatsii», 11.01.1999 g., N 2, st. 234. v red. ot 25.12.2012 g.

9. Federal'nyi zakon ot 17.06.1996 g. N 74-FZ «O natsional'no-kul'turnoi avtonomii» // «Sobranie zakonodatel'stva Rossiiskoi Federatsii», 17.06.1996 g., N 25, st. 2965. v red. ot 04.11.2014 g. 
10. Federal'nyi zakon ot 22.10.2004 g. N 125-FZ «Ob arkhivnom dele v Rossiiskoi Federatsii» // «Sobranie zakonodatel'stva Rossiiskoi Federatsii», 25.10.2004 g. N 43 st. 4169. v red. ot 04.10.2014 g.

11. Federal'nyi zakon ot $25.06 .2002 \mathrm{~g}$. N 73-FZ «Ob ob"ektakh kul'turnogo naslediya (pamyatnikakh istorii i kul'tury) narodov Rossiiskoi Federatsii» // "Rossiiskaya gazeta", 29.06.2002 g. N 116-117. v red. ot 23.07.2013 g.

12. Federal'nyi zakon ot 13.12.1996 g. N 150-FZ «Ob oruzhii» // "Sobranie zakonodatel'stva RF", 16.12.1996, N 51, st. 5681. v red. ot 21.07.2014 g.

13. Federal'nyi zakon ot 24.11.1996 g. N 132-FZ «Ob osnovakh turistskoi deyatel'nosti v Rossiiskoi Federatsii» // "Sobranie zakonodatel'stva RF", 02.12.1996, N 49, st. 5491. v red. ot 03.05.2012 g.

14. Zakon RF ot 9.10.1992 g. N 3612-I «Osnovy zakonodatel'stva Rossiiskoi Federatsii o kul'ture» // "Rossiiskaya gazeta", 17.11.1992 g. N 248. v red. ot 21.07.2014 g.

15. Ukaz Prezidenta RF ot 22.04.2013 g. № 375 «0 provedenii v Rossiiskoi Federatsii Goda kul'tury» // Sobr. zakonodatel'stva Ros. Federatsii. 2013. № 17, st. 2112.

16. Proekt Federal'nogo zakona "O kul'ture v Rossiiskoi Federatsii" // Internet-portal "Rossiiskoi Gazety".-2011.-26 oktyabrya.Rezhim dostupa URL: http://www.rg.ru/2011/10/26/kultura-site-dok.html (data obrashcheniya 12.10.2015 g.).

17. Proekt Federal'nogo zakona «O vnesenii izmenenii v Federal'nyi zakon "Ob otsenochnoi deyatel'nosti v Rossiiskoi Federatsii"» № 215711-4.

18. Doklad o rezul'tatakh i osnovnykh napravleniyakh deyatel'nosti Ministerstva kul'tury Rossiiskoi Federatsii za 2014 god i zadachakh na 2015 god. [Elektronnyi resurs]// Rezhim dostupa: http://www.donland.ru/ Default. aspx?pageid=78774 (data obrashcheniya 12.10.2015).

19. Gosudarstvennyi doklad o sostoyanii kul'tury v Rossiiskoi Federatsii v 2013 godu [Elektronnyi resurs]// Rezhim dostupa: http://mkrf.ru/upload/mkrf/mkdocs2014/doklad_block.pdf Data obrashcheniya 12.10.2015.

20. Rekomendatsiya YuNESKO «Ob uchastii i vklade narodnykh mass v kul'turnuyu zhizn'» (Nairobi, 26 noyabrya 1976 g.) // Mezhdunarodnye normativnye akty YuNESKO.-M.: Logos, 1993. S. 340 - 352.

21. Kalinin V.V. Kul'tura v sisteme razvitiya sovremennogo rossiiskogo obshchestva / V.V.Kalinin // Kul'tura: upravlenie, ekonomika, pravo.-2007.-N 4.-S.15.

22. Podbolotov P.A. Universitet kul'tury i iskusstv kak model' kul'turnogo prostranstva Rossii / P.A. Podbolotov // Kul'tura: upravlenie, ekonomika, pravo.-2009.-N 2.-S.33.

23. Khairullin, R. A. Osnovy gosudarstvennoi kul'turnoi politiki [Tekst] : realizatsiya v sfere natsional'no-kul'turnykh otnoshenii / R. A. Khairullin.//Probely v rossiiskom zakonodatel'stve.-2015.-№ 1.-S. 30 - 32.

24. Vedomosti SND RF i VS RF. 1992. № 46, st. 2615; 2009. № 52, ch. 1, st. 6411.

25. Berg L.N. Osnovnye etapy rossiiskoi pravovoi politiki v sfere nauchnoi deyatel'nosti // Politika i Obshchestvo. - 2014. 10. - C. 1155 - 1160. DOI: 10.7256/1812-8696.2014.10.11441.

26. Manzarkhanova L.V. Mezhdistsiplinarnyi podkhod v issledovanii traditsionnoi kul'tury // Filosofiya i kul'tura. - 2014. 2. - C. 190 - 194. DOI: 10.7256/1999-2793.2014.2.10766. 